\title{
Foraging for covered and uncovered food on a radial maze
}

\author{
TAMARA J. ILERSICH \\ University of Western Ontario, London, Ontario, Canada \\ DWIGHT S. MAZMANIAN \\ Concordia University, Montreal, Quebec, Canada \\ and \\ WILLIAM A. ROBERTS \\ University of Western Ontario, London, Ontario, Canada
}

\begin{abstract}
Rats were trained to forage for food on a four-arm radial maze. Each arm of the maze was defined as a patch and contained four feeding stations. Each patch contained a total of $2045-\mathrm{mg}$ food pellets, with the first feeding station in each patch baited with 1 pellet and the remaining stations baited with 1, 5, or 13 pellets. In Experiment 1, one group of rats was tested with feeders open and food readily accessible, and another group was tested with metal covers on the feeders, which necessitated extra time to gain access to food. With open feeders, the rats visited each feeder in a patch in the order in which they encountered the feeders, from the center of the maze to the end of the arm. The rats in the group with the covered feeders often visited the feeders containing 5 or 13 pellets first and the feeders containing 1 pellet last. In Experiment 2, it was found that the rats switched readily between these two foraging strategies when tested with covered and open feeders on alternate sessions. The extra time and effort required to uncover food appeared to produce selective foraging in rats.
\end{abstract}

Animals searching through a habitat may often find food concentrated in particular locations or patches. Furthermore, concentrations of food may vary in quantity and quality between patches and between locations within patches. Models of optimal foraging have been developed to indicate how an animal should forage in order to maximize the amount of energy gained per unit of time (Krebs, 1978; Pyke, Pulliam, \& Charnov, 1977; Stephens \& Krebs, 1986). As foraging behavior approaches optimality, curves relating accumulated energy to time spent foraging should rise at faster rates. Optimal foraging theory suggests decision rules animals might use, based on environmental constraints, in order to maximize energy intake (Schoener, 1987).

Several investigators recently have suggested that the radial maze apparatus may be used to study foraging (Batson, Best, Phillips, Patel, \& Gilleland, 1986; Melcer \& Timberlake, 1985). There are several reasons why the radial maze may be a particularly desirable instrument for studying foraging in rats. One reason is that the radial structure of the maze, with all arms returning to a central area, mimics to a certain extent the systems of burrows

This research was supported by National Sciences and Engineering research Council Grant A7894 to W. A. Roberts. We wish to thank Michelle Carrie and Jody Brown for their help with the initial stages of the research. Requests for reprints should be sent to W. A. Roberts, Department of Psychology, University of Western Ontario, London, Ontario N6A 5C2, Canada. in which wild rats are found (Lore \& Flannelly, 1978). Considerable evidence has by now accumulated to indicate strong use of working and reference memory in rats traveling through radial mazes (Olton, 1978; Roberts, 1984). Working memory has been demonstrated by the rat's ability to keep track accurately of places visited on the maze and thus avoid reentry into arms where food has already been consumed (Olton \& Samuelson, 1976). When certain arms on a radial maze are consistently baited with food, rats show excellent reference memory by learning to restrict their choices to the baited arms only (Olton \& Papas, 1979). Recent evidence also suggests that rats may be very sensitive to variations in the quantity or quality of consumable items placed at the end of maze arms. Hulse and O'Leary (1982) placed different amounts of food at the ends of arms on a four-arm maze and found that rats learned to choose the arms in decreasing order of food value. Both Batson et al. (1986) and Melcer and Timberlake (1985) have shown that rats will prefer to enter an arm containing a palatable substance and avoid an arm containing an aversive substance, such as a saccharin solution previously used to condition a taste aversion.

In the experiments reported here, a four-arm radial maze was used to study foraging in rats. Each arm on the maze was defined as a patch, and a unique feature of the maze was the placement of four feeding stations on each arm. While the total amount of food placed in each patch was constant, the amount of food varied from 
one feeding station to another within the patches, with the distribution of food staying constant throughout an experiment. A constraint on foraging was introduced by placing heavy covers over the food cups for one group of rats. These animals then had to spend some time and exert some effort in order to uncover the food. Animals in a control group foraged with open feeders. We were particularly interested in the pattern of foraging that the rats would show in each patch, with and without the requirement of uncovering food. The experiments revealed quite different foraging strategies in animals with and without covered food.

\section{EXPERIMENT 1}

\section{Method}

Subjects. The subjects were 12 male Long-Evans rats, 70-100 days old. The rats were housed separately in wire cages and kept under a 16:8-h light:dark schedule, with light turned on in the housing room at $6 \mathrm{a.m}$. and off at $10 \mathrm{p} . \mathrm{m}$. Each subject was kept at approximately $85 \%$ of its free-feeding weight. Testing was carried out between 3 p.m. and 7 p.m. six days a week.

Apparatus. A top view of the four-arm radial maze appears in Figure 1. The maze was constructed of plywood and painted black. The central platform was $35 \mathrm{~cm}$ in diameter, and each arm was $76 \mathrm{~cm}$ long and $9 \mathrm{~cm}$ wide. Along the left side of each arm, four feeding stations, each measuring $5 \times 5 \mathrm{~cm}$, were located, spaced $13 \mathrm{~cm}$ apart edge to edge. A plastic feeding cup, measuring $3.2 \mathrm{~cm}$ in diameter and $1.2 \mathrm{~cm}$ deep, was attached to each feeding station. Pieces of wooden dowling supported the arms and the central platform of the maze, $60 \mathrm{~cm}$ above the floor. The covers placed on top of the feeders were square pieces of metal that each weighed $73 \mathrm{~g}$, measured $4 \mathrm{~cm}$ on each side, and were $.6 \mathrm{~cm}$ thick.

The maze was placed on one side of a $3.1 \times 3.1 \mathrm{~m}$ room that contained one door and was illuminated by two enclosed, overhead

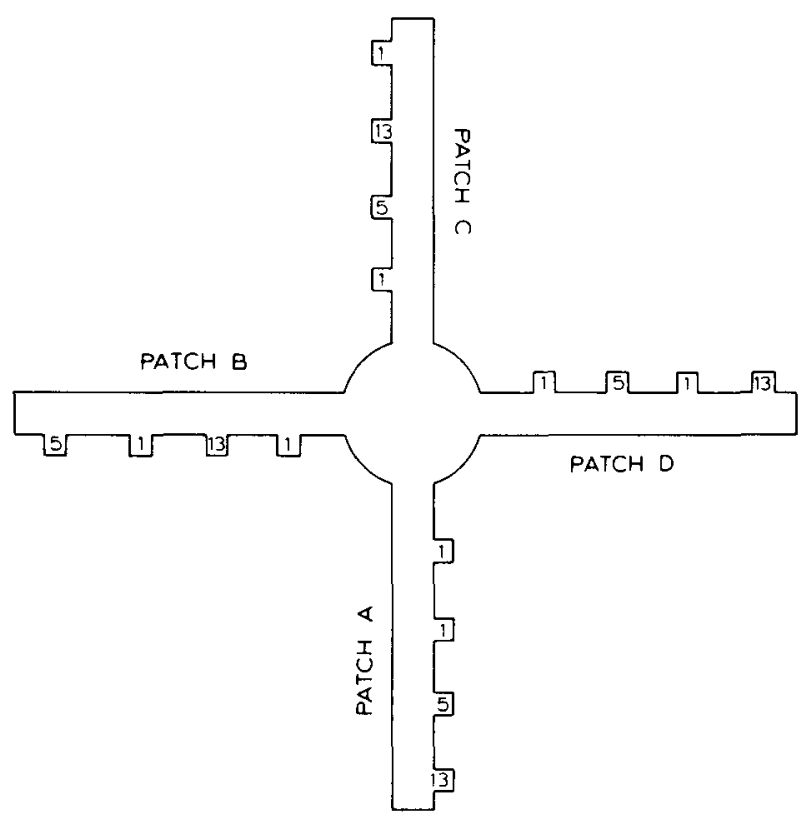

Figure 1. A top view of the four-arm radial maze. Each arm is labeled as a patch, with four feeding stations in each patch. The distributions of 20 food pellets among the feeders within the patches are shown by the numbers at each feeding station. fluorescent lighting units. A blind made of gray posterboard mounted on a wooden frame and measuring $111 \mathrm{~cm}$ wide and $145 \mathrm{~cm}$ high was placed adjacent to the maze. The experimenter sat behind the blind and observed each subject's behavior through a small hole in the blind. Beside the experimenter was a desk containing a Commodore 64 computer, a monitor, a printer, and a disk drive. The blind, the door, and pictures on the wall provided a number of extramaze cues. White noise was played through an overhead speaker throughout the experimental sessions.

Procedure. The rats were divided randomly into two groups of 6 animals each, with one group designated the covers group and the other group designated the open group. During preliminary training, the rats were handled on an open field and allowed to consume 45-mg Noyes pellets from food cups like those on the maze. The covers group was also trained to push metal covers off the food cups in order to obtain pellets. The covers initially were placed over only half of the cup; the area covered was then increased gradually until the animal would push the cover off of a completely covered cup. After open-field training, the animals were given two or three days of preliminary training on the maze. All feeders were baited with three 5-mg pellets, and all rats were allowed to forage until all of the feeders had been visited. All of the animals in the open group ate readily from the feeders by the second day. Some animals in the covers group initially failed to push covers off of the feeders on initial exposure to the maze, but they were responding well by the third day.

It can be seen in Figure 1 that the patches or arms were labeled patches A, B, C, and D. Within each patch, the feeding stations were numbered $1-4$, starting from the center of the maze. Thus, each feeding station on the maze had a separate code, such as A3, B1, C4, or D2. At the beginning of each daily foraging session, the feeders in each patch were baited with a total of 2045 -mg pellets. The first feeder in the patch always contained 1 pellet, and the three subsequent feeders contained 1, 5, and 13 pellets. One distribution of pellets is shown by the numbers of pellets printed on the feeding stations in Figure 1. The assignment of distributions of pellets to patches varied among animals, but the order of number of pellets from Feeding Station 1 to Feeding Station 4 was always 1-1-5-13 in one patch, 1-13-1-5 in a second patch, 1-5-13-1 in a third patch, and $1-5-1-13$ in the fourth patch. For individual subjects, the pattern of pellets in each patch was kept the same throughout testing.

At the beginning of each session, the experimenter placed the subject on the center of the maze and then retired behind the blind. Each time an animal visited a feeder, the experimenter entered the feeder's code into the computer. When all of the feeders had been visited or a subject had not visited a feeder for $5 \mathrm{~min}$, the subject was removed from the maze and returned to its home cage. A printout from the computer provided an ordinal record of the subject's visits to feeding stations on the maze and the time of arrival at each feeding station. Each rat was tested for 10 sessions.

\section{Results and Discussion}

By the second or third session, very different patterns of foraging emerged for animals in the covers group as opposed to animals in the open group. In the open group, all the animals tended to visit the feeding stations and consume the contents of the feeders in order, from Station 1 closest to the center to Station 4 at the end of the arm. By contrast, the rats in the covers group tended to go first to the stations that contained feeders with 5 or 13 pellets. After pushing the covers off of these feeders and consuming the pellets, the subjects sometimes visited the feeders in the patch with 1 pellet; but frequently, the subjects left the patch without visiting the 1-pellet feeders and went to another previously unvisited patch. After visiting all 
of the feeding stations that contained 5 or 13 pellets, the rats in the covers group returned to previously visited patches to consume pellets in any yet unvisited feeders that contained only 1 pellet. On some occasions, however, these animals simply would not return to patches with unvisited single-pellet feeders and were removed from the maze after 5 min had elapsed since the last visit to a feeding station.

In Table $1,4 \times 4$ tables are shown for performance of open and covers rats within each patch. The frequencies shown in the tables reflect the order of visits to Feeders 1, 2, 3, and 4 on the first entry into the patch on Days 2-10. Inspection of the tables for the open group reveals that most visits fall along the minor diagonal of the tables. This pattern indicates the linear search pattern used by animals in the open group; the first feeder was chosen first, the second feeder second, and so forth. The total visits to each feeder show that rats in the open group tended to visit all of the feeding stations on their first visit to the patch. The tables for the covers groups show a different pattern. While the rats in the covers group occasionally made their initial visit to the first feeder in a patch, they more frequently bypassed the first feeder and visited the remaining three feeders. Among the remaining three, they most frequently visited the feeders containing 5 or 13 pellets, and least frequently visited the second feeder that contained 1 pellet. Furthermore, the total feeders visited on first patch entry was substantially less in the covers group than in the open group. Of the 16 possible feeders that could be visited on first entry into the four patches on the maze, the open group visited 13.7 mean feeders, and the covers group visited a mean of 10.2 feeders; these means differed significantly $[t(10)=2.65$, $p<.05]$.

Since each rat visited at least one feeder on first patch entry, the percentages of first choices of the different feeders were determined for each group. The animals in the open group chose the first feeder, which contained 1 pellet, on $85.5 \%$ of their choices, whereas the coversgroup subjects chose the first feeder on $23.1 \%$ of their choices, and this difference was highly significant $[t(10)$ $=5.95, p<.01]$. The feeder containing 13 pellets was chosen first on $39.5 \%$ of patch entries by the covers group and on $3.3 \%$ of entries by the open group, and this difference too was significant $[t(10)=4.56, p<.01]$. The feeder containing 5 pellets was chosen first on $29.6 \%$ of patch entries by the covers group, and this value significantly exceeded the $9.8 \%$ first choices made by the open group $[t(10)=4.26, p<.01]$. Finally, both groups showed only a small percentage of choices of the second feeder containing 1 pellet $-1.4 \%$ for the open group and $7.8 \%$ for the covers group-but the difference between these values was significant $[t(10)=2.49, p<.05]$. Within the covers group, the feeders containing 13 or 5 pellets were both chosen first significantly more often than the second feeder containing 1 pellet $[t(5) \geq 3.46$, $p<.05]$; the feeder containing 13 pellets was not chosen first significantly more often than the feeder containing 5 pellets $[t(5)=1.68, p>.05]$.

The effects of the different patterns of foraging on pellets consumed is shown in Figure 2. Mean pellets consumed is plotted as a function of the first, second, third, and fourth feeding stations visited in each patch; visits to feeding stations included both feeders visited on first

Table 1

Frequency of Visits to Feeders 1-4 on Choices 1-4, with Separate Tables Shown for Each Arm (Patch) Sequence of Number of Food Pellets (Experiment 1)

\begin{tabular}{|c|c|c|c|c|c|c|c|c|c|c|}
\hline \multirow[b]{3}{*}{ Feeder } & \multicolumn{10}{|c|}{ Group } \\
\hline & \multicolumn{5}{|c|}{ Open Choice } & \multicolumn{5}{|c|}{ Covers Choice } \\
\hline & 1 & 2 & 3 & 4 & Total & 1 & 2 & 3 & 4 & Total \\
\hline \multicolumn{11}{|c|}{ Arm 1-1-5-13 } \\
\hline $1(1)$ & 47 & 0 & 0 & 0 & 47 & 10 & 0 & 1 & 4 & 15 \\
\hline $2(1)$ & 3 & 40 & 0 & 1 & 44 & 9 & 8 & 6 & 1 & 24 \\
\hline $3(5)$ & 3 & 6 & 38 & 0 & 47 & 18 & 20 & 7 & 0 & 45 \\
\hline $4(13)$ & 1 & 2 & 6 & 36 & 45 & 17 & 18 & 9 & 7 & 51 \\
\hline \multicolumn{11}{|c|}{ Arm 1-5-1-13 } \\
\hline $1(1)$ & 45 & 2 & 0 & 0 & 47 & 19 & 0 & 1 & 2 & 22 \\
\hline $2(5)$ & 8 & 43 & 1 & 0 & 52 & 17 & 24 & 2 & 0 & 43 \\
\hline $3(1)$ & 0 & 3 & 39 & 2 & 44 & 1 & 10 & 16 & 0 & 27 \\
\hline $4(13)$ & 1 & 3 & 5 & 39 & 48 & 17 & 12 & 6 & 14 & 49 \\
\hline \multicolumn{11}{|c|}{ Arm 1-5-13-1 } \\
\hline $1(1)$ & 42 & 0 & 0 & 0 & 42 & 14 & 0 & 2 & 2 & 18 \\
\hline $2(5)$ & 10 & 41 & 0 & 0 & 51 & 17 & 19 & 4 & 1 & 41 \\
\hline $3(13)$ & 1 & 10 & 38 & 1 & 50 & 18 & 20 & 14 & 0 & 52 \\
\hline $4(1)$ & 0 & 1 & 8 & 35 & 44 & 5 & 4 & 9 & 10 & 28 \\
\hline \multicolumn{11}{|c|}{ Arm 1-13-1-5 } \\
\hline $1(1)$ & 49 & 0 & 0 & $\mathbf{0}$ & 49 & 7 & 0 & 1 & 6 & 14 \\
\hline 2(13) & 4 & 43 & 0 & 0 & 47 & 33 & 14 & 2 & 0 & 49 \\
\hline $3(1)$ & 0 & 4 & 37 & 1 & 42 & 2 & 14 & 8 & 0 & 24 \\
\hline $4(5)$ & 0 & 0 & 5 & 36 & 41 & 12 & 20 & 12 & 5 & 49 \\
\hline
\end{tabular}




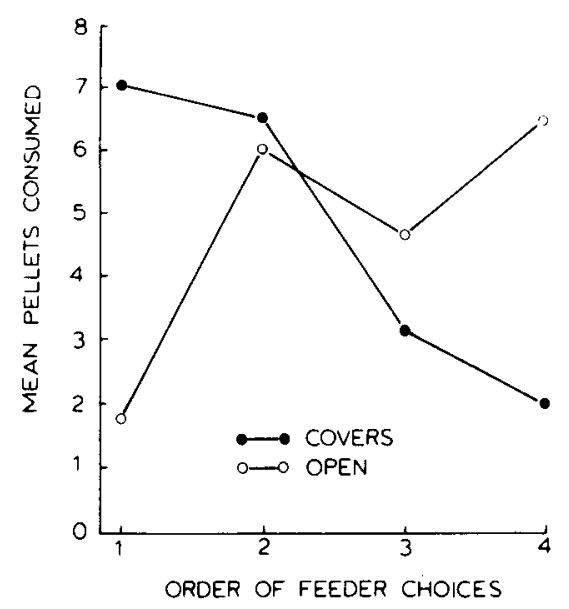

Figure 2. Curves showing the mean pellets consumed at the first, second, third, and fourth feeder visited by rats in the covers and open groups. Each point is based on pellets consumed, summed over all four arms and Days 2-10 of testing in Experiment 1.

patch entry and those visited on subsequent visits to a patch. The means were based on total pellets consumed at each ordinal position, summed over patches and over Sessions 2-10. Since animals in the open group tended to eat from feeders in the order in which they were encountered on an arm, they obtained little food in the first feeder visited, and the pellets consumed increased at the later feeders visited. The animals in the covers group obtained most of their pellets at the first two feeding stations visited, with far fewer pellets obtained at the third and fourth feeding stations visited in a patch. Comparisons of the mean pellets consumed showed significant differences between the covers and open groups at the first choice $[t(10)=5.25, p<.01]$ and the fourth choice $[t(10)=5.96, p<.01]$, but not at Choices 2 and $3[t(10)$ $\leq 1.84, p>.05]$.

The tendency for animals in the covers group to visit feeding stations with the largest quantities of food first led this group to accumulate pellets faster than the open group over successive choices. Since pushing metal plates off of the feeders required extra time in the covers group, an interesting comparison involves the pellets accumulated as a function of elapsed time spent foraging. For each subject in the covers and open groups, the median time of arrival at successive feeding stations was determined over Sessions 2-10. The mean of the median times of arrival at successive feeders was then calculated separately for animals in the covers and open groups. The curves showing mean cumulative pellets consumed as a function of mean median time of arrival at successive feeders are shown in Figure 3. The curves for the covers and open groups, which are close together, show only a slight advantage for the open group over the covers group.

With a few days of training, rats in the covers group uncovered food rapidly, taking 1-2 sec to remove the food cover. However, this extra effort and time had considerable impact on foraging behavior. While the rats with open feeders visited feeders and consumed their contents in the order in which they were encountered in each patch, the rats required to work to uncover hidden food gave priority to the feeders containing the largest quantities of food. Although the animals in the covers group got to the larger quantities of food sooner in terms of order of feeding stations visited, they then had to spend more time uncovering the food. The curves shown in Figure 3 suggest that feeder selectivity and food uncovering time traded off to allow the covers subjects to accumulate pellets almost as rapidly as the open subjects. In other words, the extra time and effort required of the covers animals necessitated selective foraging in order to maximize the rate of food acquisition.

\section{EXPERIMENT 2}

In Experiment 1, separate groups of rats encountered covered or open feeders and demonstrated different foraging strategies. In a natural setting, however, the same animal may encounter different habitats in which handling requirements vary. Foraging theory suggests that a forager will adapt its foraging strategy to the demands placed upon it by its current habitat. In Experiment 2, we examined the flexibility of rats' foraging strategies by testing the same animals on alternate days with covered and open feeders. If rats are capable of rapid adaptation of strategy to the current conditions, we would expect to find rats selecting feeders with the largest quantities of food first on days with covered feeders and using the linear search pattern on days with open feeders. If the changing feeder conditions should create confusion or interference, we might observe rats using inappropriate strategies or adopting one strategy and using it throughout testing.

We may inquire as to the basis of the rats' selective foraging strategy in the covered food condition. One possibility is that the rats used spatial memory for the loca-

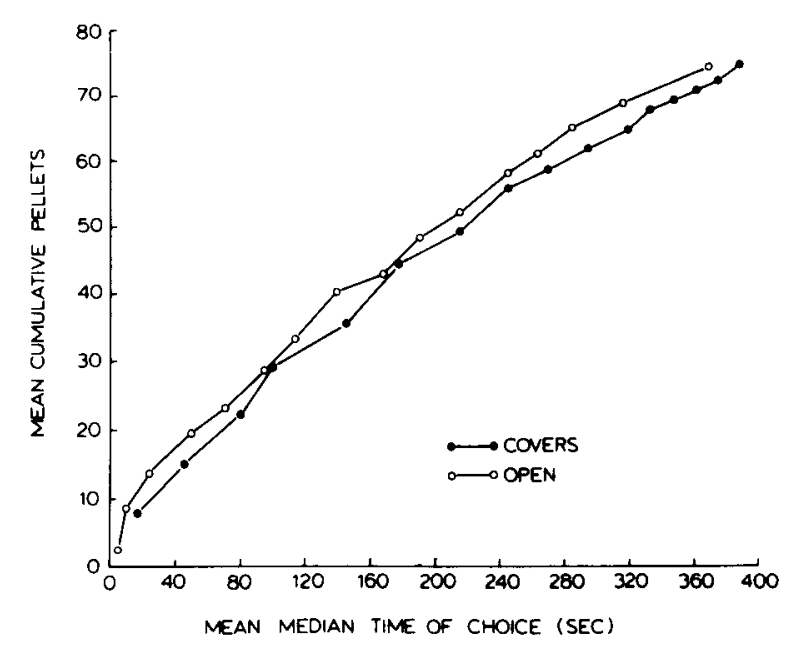

Figure 3. Mean cumulative pellets consumed as a function of mean median time of arrival at successive feeding stations. Each point is based on data from Days 2-10 of Experiment 1. 
tions of different amounts of food. Another possibility is that the rats were able to smell the different quantities of food and were led by olfactory cues to the feeders with larger quantities of food. As a control test, the animals were tested at the end of the experiment with equal numbers of food pellets placed in covered feeders. If the subjects were using odor cues to locate large quantities of food, selective foraging patterns should have deteriorated relative to the patterns in tests with different amounts in the feeders. Selective foraging patterns ought to have been maintained, however, if the animals were using spatial memory.

\section{Method}

Subjects. Seven naive male Long-Evans rats were used. They were kept at $85 \%$ of free-feeding weights throughout the experiment and were housed under the same conditions as the subjects in Experiment 1.

Apparatus. The four-arm radial maze used in the first experiment was used in Experiment 2.

Procedure. All of the subjects were tested for a total of 28 days. On Days 1-20, the feeders in each patch contained 1, 1, 5, and 13 pellets, with the first feeder always containing 1 pellet. The pattern of pellet distribution among the remaining three feeders varied between patches, as depicted in Figure 1. Different patterns were assigned to different patches among subjects, but the numbers of pellets placed in different feeders remained constant across test days for any given subject. During the first 20 days of testing, the feeders were covered or open on alternate days. On odd days, the animals always encountered open feeders, and, on even days, the animals always encountered covered feeders.

On Days 21-28, all tests were carried out with covered feeders. On Day 21 and Days 23-27, the standard distributions of food pellets used during the first 20 days of testing were again used (Con- dition 1-1-5-13). On Days 22 and 28, control tests were carried out by placing 5 pellets in each feeder in each patch (Condition 5-5-5-5). Throughout the 28 days of testing, performance was observed and recorded in the same manner as in Experiment 1.

\section{Results and Discussion}

The subjects showed striking differences between foraging strategies on days with open food stations and foraging strategies on days with covered food stations. With open feeders, the rats almost always used the linear search pattern and visited the feeders in order, from the beginning of an alley to its end. On the alternate days with covered feeders, the rats switched to the selective strategy seen in the covers group in Experiment 1. The feeder choices on first entry into arms are summarized in Table 2 over Days 3-20. Almost all of the choices made in the open feeders condition are found in the minor diagonal of the $4 \times 4$ tables for each arm. The tables suggest that in the covers condition, the animals frequently bypassed the first feeder on an arm and selected one of the remaining three feeders containing either 5 or 13 pellets. The mean feeders visited per session on first arm entry was 15.7 in the open condition and 11.0 in the covers condition, and these means differed significantly $[t(6)=6.99$, $p<.01]$.

An analysis of first feeders visited on initial visits to each arm showed that the rats chose the first feeder, which contained 1 pellet, on $98.8 \%$ of the arm entrances in the open condition. With covered feeders, there were significantly fewer first feeder choices, $27.0 \%[t(6)=11.66$, $p<.05]$. The feeder containing 13 pellets was chosen first on $29.0 \%$ of the arm visits with covered feeders and

Table 2

Frequency of Visits to Feeders 1-4 on Choices 1-4, with Separate Tables Shown for Each Arm (Patch) Sequence of Number of Food Pellets (Experiment 2)

\begin{tabular}{|c|c|c|c|c|c|c|c|c|c|c|}
\hline \multirow[b]{3}{*}{ Feeder } & \multicolumn{10}{|c|}{ Condition } \\
\hline & \multicolumn{5}{|c|}{ Open Choice } & \multicolumn{5}{|c|}{ Covers Choice } \\
\hline & 1 & 2 & 3 & 4 & Total & 1 & 2 & 3 & 4 & Total \\
\hline \multicolumn{11}{|c|}{ Arm 1-1-5-13 } \\
\hline $1(1)$ & 62 & $\mathbf{0}$ & 0 & 0 & 62 & 17 & 0 & 1 & 1 & 19 \\
\hline $2(1)$ & 1 & 62 & 0 & 0 & 63 & 7 & 5 & 6 & 0 & 18 \\
\hline $3(5)$ & 0 & 1 & 62 & 0 & 63 & 31 & 13 & 14 & 0 & 58 \\
\hline $4(13)$ & 0 & $\mathbf{0}$ & 1 & 62 & 63 & 8 & 31 & 8 & 14 & 61 \\
\hline \multicolumn{11}{|c|}{ Arm 1-5-1-13 } \\
\hline $1(1)$ & 63 & 0 & 0 & 0 & 63 & 16 & 0 & $\mathbf{0}$ & 2 & 18 \\
\hline $2(5)$ & 0 & 63 & 0 & 0 & 63 & 33 & 16 & 2 & 0 & 51 \\
\hline $3(1)$ & $\mathbf{0}$ & 0 & 61 & 0 & 61 & 4 & 10 & 10 & 4 & 28 \\
\hline $4(13)$ & 0 & 0 & 0 & 61 & 61 & 10 & 30 & 12 & 10 & 62 \\
\hline \multicolumn{11}{|c|}{ Arm 1-5-13-1 } \\
\hline $1(1)$ & 62 & 0 & 0 & 0 & 62 & 22 & 0 & 2 & 9 & 33 \\
\hline $2(5)$ & 1 & 61 & 0 & 0 & 62 & 31 & 21 & 2 & 0 & 54 \\
\hline $3(13)$ & 0 & 1 & 61 & 0 & 62 & 10 & 28 & 23 & 0 & 61 \\
\hline $4(1)$ & $\mathbf{0}$ & 0 & 1 & 61 & 62 & 0 & 9 & 23 & 21 & 53 \\
\hline \multicolumn{11}{|c|}{ Arm 1-13-1-5 } \\
\hline $1(1)$ & 62 & 0 & 0 & 0 & 62 & 13 & 0 & 1 & 7 & 21 \\
\hline $2(13)$ & 1 & 62 & 0 & 0 & 63 & 45 & 14 & 0 & 0 & 59 \\
\hline $3(1)$ & 0 & 1 & 57 & 1 & 59 & 1 & 24 & 11 & 1 & 37 \\
\hline $4(5)$ & 0 & 0 & 3 & 57 & 60 & 4 & 21 & 28 & 8 & 61 \\
\hline
\end{tabular}


on $.4 \%$ of the arm visits with open feeders, and this difference was significant $[t(6)=5.96, p<.01]$. The 5-pellet feeder also was chosen first significantly more often under the covered feeders condition, $39.3 \%$, than it was under the open feeders condition, .4\% $[t(6)=5.26$, $p<.01]$. On each arm, the second feeder that contained 1 pellet was chosen first infrequently under both the covered feeders condition (4.8\%), and the open feeders condition $(.4 \%)$, but the difference was significant $[t(6)=3.87, p<.01]$. Within the covers condition, the rats chose the 13- and 5-pellet feeders first significantly more often than they did the second feeder that contained 1 pellet $[t(6) \geq 4.46, p<.01]$, but the frequency of first choices did not differ significantly between the 5- and 13pellet feeders $[t(6)=1.02, p>.05]$.

On odor control tests carried out over Days 21-28, the rats were tested with covered feeders, with the usual differential distributions of pellets in the feeders on each arm on Day 21 and Days 23-27 (Condition 1-1-5-13). On Days 22 and 28, 5 pellets were placed in each feeder on each arm (Condition 5-5-5-5). The initial feeders in each patch were chosen first on $36.9 \%$ of initial alley visits in Condition 1-1-5-13, and on $42.8 \%$ of first alley visits in Condition 5-5-5-5. The feeders containing 13 pellets were chosen first on $31.5 \%$ of arm entrances under Condition 1-1-5-13; the feeders containing 5 pellets were chosen first on $23.2 \%$. Under Condition 5-5-5-5, the feeders that normally contained 13 or 5 pellets were chosen first on $26.8 \%$ and $16.1 \%$, respectively, of arm entrances. None of the differences between these mean percentages for the 1-1-5-13 and 5-5-5-5 conditions was significant $[t(6) \leq 1.68, p>.05]$. The second 1-pellet feeder on each arm was chosen on $8.3 \%$ of arm entrances under Condition 1-1-5-13; the feeders that normally contained the second single pellet were chosen first on $14.3 \%$ of arm entrances in the odor control condition. These means differed significantly according to a one-tailed test $[t(6)=2.20, p<.05]$. This pattern of findings does not appear to argue strongly for or against the use of odor cues. Although the percentages of first choices of feeders designated as containing different quantities of food generally did not differ significantly, the differences observed were in the direction predicted by the odor hypothesis. Furthermore, the one significant difference between the two conditions also favored the odor interpretation.

The plots of mean pellets consumed against successive feeders visited over Days 3-20 show curves similar to those presented in Figures 2 and 3; they will not be presented here for sake of economy. The findings of Experiment 2 indicate that the differences in foraging strategies found between the groups with covered and groups with open food in Experiment 1 can easily be demonstrated for the same animals. The rats switched readily between a linear search strategy and a selective feeder strategy from day to day, depending on whether the feeders were open or covered. There was no suggestion that the animals confused these two foraging strategies.

\section{GENERAL DISCUSSION}

One aspect of foraging theory concerns the conditions under which animals make decisions about where and when to search for and consume food. The theory argues that animals have been genetically programmed to make decisions that will tend to maximize energy gain and minimize expenditure of energy and time (Krebs \& McCleery, 1984; Pyke et al., 1977; Stephens \& Krebs, 1986). In an attempt to create a laboratory analogue of a patchy environment for rats, we placed multiple feeding stations on the arms of a four-arm radial maze and defined each arm as a patch. All patches were equivalent in terms of the total food they contained, but the feeders within the patches varied according to the amounts of food they contained. When heavy covers were placed over the feeders, the rats were forced to expend time and effort to uncover the food.

The interesting observation made in these experiments was that the rats foraged selectively when the food was covered but not when the feeders were open. The observation that the rats visited the covered feeders containing the largest quantities of food first would seem to be a good example of optimal foraging. Since time and energy was expended in uncovering food, the rate of food consumption was maximized by visiting the most valued feeders first. When the feeders were open, the rats simply visited feeding stations in order, from Station 1 to Station 4 in each patch. It may be wondered why the animals did not also go first to the feeding stations with the largest amounts of food when the feeders were open. Functions describing the tradeoff between quantity of reinforcement and delay may account for this behavior (Logan, 1965). When confronted with the choice between obtaining 1 pellet immediately at Station 1 and delaying reinforcement for a larger amount at Station 2, 3, or 4, the rats may have favored the immediate reinforcement. When all the feeders were covered, however, reinforcement was delayed at all feeders, and the delay versus quantity of reinforcement tradeoff may then have favored selective foraging. A similar kind of prediction follows from the diet model of optimal foraging theory (Fantino \& Abarca, 1985). Animals randomly encountering prey of varying profitability should show increasing specialization or selectivity as the common handling time of food items increases.

Selective foraging among feeders when food was covered allowed the animals to accumulate food at a momentarily faster rate than would have been the case if a linear foraging strategy had been followed, as seen in Figure 2. Over an entire session, however, the total food consumed was about the same for the open and covers conditions, and the overall rate of food acquisition was about the same for selective and linear foraging. Why did the rats continue to forage selectively over repeated sessions with covered feeders, if all the pellets could be obtained with the linear strategy? The strategy observed with covered food may be more appropriate in a natural setting. That is, rats 
foraging for food that requires some effort to gain access to in a natural habitat may be interrupted at any moment, by a predator or by a conspecific that will compete for the available food. Under these conditions, the best strategy is to take the largest caches of food first and the smaller ones last.

Although the rats encountering covered food appeared to forage selectively, they did not show perfect discrimination among the feeders within patches. The feeders were not always chosen in decreasing order relative to the amount of food they contained. The animals still visited the initial feeder in a patch on occasion, but they more commonly bypassed the initial feeder and visited one of the more distant, remaining feeders. One strategy the animals could have used was to skip the first feeder and visit the remaining three either randomly or in order. This strategy would not involve discrimination among the last three feeders in a patch. The data suggest, however, that the rats were discriminating between the second feeder containing 1 pellet and the feeders containing 5 or 13 pellets. In both Experiments 1 and 2, the rats chose the 5- or 13-pellet feeders first more frequently than the 1pellet feeder, but they did not show differential frequency of first visits to 5- or 13-pellet feeders. It may be that the rats did not discriminate well between 5- and 13-pellet feeders, or it may be that these amounts had equivalent incentive value.

The two most likely explanations for discrimination between covered feeders containing 1 as opposed to 5 or 13 pellets are odor cues and spatial memory. A control test for the use of odor cues in Experiment 2 was inconclusive with respect to which of these mechanisms might be responsible for the selective foraging in these experiments. Given recent evidence of spatial memory in rats for quantity or quality of food (Batson et al., 1986; Hulse \& O'Leary, 1982; Melcer \& Timberlake, 1985), it seems quite possible that the rats in our experiments were using memory to some extent to keep track of the locations of different amounts of food. Furthermore, since the arrangement of amounts of food contained in feeders varied from arm to arm, the imperfect discrimination observed could have arisen from retroactive and proactive interference effects (Roberts, 1981; Roberts \& Dale, 1981). The possibility that the rats used odor cues or odor cues in conjunction with memory remains a possibility.

On the basis of these findings, we suggest that the radial maze is an excellent tool for studying foraging behavior in rats. The pattern of the maze may be important as an analogue of the natural habitat within which wild rats live and forage. The introduction of multiple feeding locations that contain different amounts of food allowed us to examine the foraging patterns by which rats exploit areas varying in food concentration. Access to food is easily manipulated by using covered or uncovered feeders, and this manipulation appears to reveal very different foraging strategies.

\section{REFERENCES}

Batson, J. D., Best, M. R., Phillsp, D. L., Patel, H., \& Gilleland, K. R. (1986). Foraging on the radial-arm maze: Effects of altering the reward at a target location. Animal Leaming \& Behavior, 14, 241-248.

Fantino, E., ABARCa, N. (1985). Choice, optimal foraging, and the delay-reduction hypothesis. Behavioral \& Brain Sciences, 8, 315-330.

HuLSE, S. H., O'LeARY, D. K. (1982). Serial pattern learning: Teaching an alphabet to rats. Joumal of Experimental Psychology: Animal Behavior Processes, 8, 260-273.

KREBS, J. R. (1978). Optimal foraging: Decision rules for predators. In J. R. Krebs \& N. B. Davies (Eds.), Behavioural ecology: An evolutionary approach (pp. 23-63). London: Blackwell.

KREBS, J. R., MCCLEERY, R. H. (1984). Optimization in behavioural ecology. In J. R. Krebs \& N. B. Davies (Eds.), Behavioural ecology (2nd ed., pp. 91-121). Sunderland, MA: Sinauer.

LOGAN, F. A. (1965). Decision-making in rats: Delay versus amount of reward. Joumal of Comparative \& Physiological Psychology, 59, 1-12.

LORE, R., Flannelly, K. (1978). Habitat selection and burtow construction by wild Rattus norvegicus in a landfill. Journal of Comparative \& Physiological Psychology, 92, 888-896.

MrlCer, T., Timberlake, W. (1985). Poison avoidance and patch (location) selection in rats. Animal Learning \& Behavior, 13, 60-68.

Outon, D. S. (1978). Characteristics of spatial memory. In S. H. Hulse, H. Fowler, \& W. K. Honig (Eds.), Cognitive processes in animal behavior (pp. 341-373). Hillsdale, NJ: Erlbaum.

Olton, D. S., \& Papas, B. C. (1979). Spatial memory and hippocampal function. Neuropsychologia, 17, 669-682.

Olton, D. S., \& Samuelson, R. J. (1976). Remembrance of places passed: Spatial memory in rats. Joumal of Experimental Psychology: Animal Behavior Processes, 2, 97-116.

Pyke, G. H., Pullam, H. R., \& Charnov, E. L. (1977). Optimal foraging: A selective review of theory and tests. The Quarterly Review of Biology, 52, 137-154.

RoBERTs, W. A. (1981). Retroactive inhibition in rat spatial memory. Animal Leaming \& Behavior, 9, 566-574.

RoBeRTs, W. A. (1984). Some issues in animal spatial memory. In H. L. Roitblat, T. G. Bever, \& H. S. Terrace (Eds.), Animal cognition (pp. 425-443). Hillsdale, NJ: Erlbaum.

RoBerTs, W. A., DALE, R. H. I. (1981). Remembrance of places lasts: Proactive inhibition and patterns of choice in rat spatial memory. Learning \& Motivation, 12, 261-281.

SCHOENER, T. W. (1987). A brief history of optimal foraging ecology. In A. C. Kamil, J. R. Krebs, \& H. R. Pulliam (Eds.), Foraging behavior (pp. 5-67). New York: Plenum Press.

StePhens, D. W. , Kreas, J. R. (1986). Foraging theory. Princeton, NJ: Princeton University Press.

(Manuscript received February 4, 1988; revision accepted for publication June 29, 1988.) 